\title{
It's time to take back the health care debate
}

$\mathrm{N}$ early everyone would agree that Canada's health care system needs substantial improvements. However, as we listen to debates over proposed solutions, we find it frustrating to hear the issue inevitably and exclusively defined for us as a war of public against private.

Instead of taking sides, we at $C M A J$ demand to know why every discourse on health care reform must inevitably degenerate into ideological warfare. We contend that the public-private framework is an artificial, self-serving distraction that stands in the way of real change.

Canadians are more concerned about the outcomes of their health care than the mechanisms that deliver it. Our system is already a mix of public and private. We have been falsely led to believe that solutions depend upon the victory of one ideology over another. They do not.

We must take back the health care debate and re-focus it to address the truly unacceptable aspects of the status quo. For example, why do millions of Canadians lack regular access to a primary care provider or adequate mental health services? And why does access to some life-prolonging cancer drugs depend on which province Canadians call home? These are the kinds of problems that should arouse the attention and concern of those who seek health care reform. In contrast, wait times for a few elective procedures, although an important issue for many, do not deserve to be the sole focus of resources and attention.

The solution begins with establishing standards that ensure high-quality care across a broad spectrum of health interventions and services, and universal access to all evidence-based essential services. And given the sizeable investment this requires, the health care system must be publicly accountable for delivering results.

These problems and their solutions are neither inherently public nor private. Yet, the perception of an irreconcilable conflict between public and private health care is being actively maintained by both sides of the debate because it serves the self-interest of the actors. Advocates for private health care play the role of the self-appointed heroes of Canada's health care system, and advocates for the public system play the staunch defenders of a Canadian value. These roles give politicians a reliable campaign platform and allow medical entrepreneurs to profit from the debate by cherry-picking and delivering high-volume, easily standardized clinical services, such as joint-replacement surgeries and magnetic resonance imaging. In so doing, they evade responsibility for articulating a compelling vision of how the health care system as a whole will benefit from allowing private-sector involvement. Maintaining the debate frees both sides from the burden of actually achieving meaningful solutions. Regardless of whether advocates support private delivery of certain clinical services, such as CMA's new president Brian Day, or oppose it, such as the Canadian Health Coalition, placing the focus on ideology rather than outcomes is a calculated diversion.

Health care stakeholders, including the general public, should no longer accept being manipulated into a debate that leads nowhere. Instead, we should hold both public and private health advocates' feet to the fire. If Canadians are asked to support an increased role for the private sector in health care, we need to hear more than rhetoric about the private sector's competitiveness and efficiency being the simple solutions to our complex problems. Elsewhere, increased privatesector involvement has invariably meant increased system complexity, greater difficulties with allocation and oversight, and higher administrative costs. Private health advocates must address the issue of how a drain of health care personnel from the public to the private tier can be avoided in the face of already limited and insufficient human resources without off-loading responsibility for such problems to the public system. And they need to address the fact that many of the businesses providing private health care services clearly violate the core value of equity in the Canada Health Act.

Equally, if Canada is to continue to exclude private delivery models, it should do so because the public system provides better care to more people while being more cost-effective rather than because we have been conditioned to fear that any circumstance in which the terms "private" and "health care" are permitted to be combined will immediately turn us into the United States.

At both the federal and provincial levels, we rely on our leaders to establish and ensure compliance with national standards in a wide range of important health care needs. Courageous federal politicians could use their fiscal leverage to bring our de facto I4-tier health care system up to these standards. We need much greater investments in health care and, in exchange for increased funding, much greater public accountability for the health care system. Politicians who maintain the public-private rhetoric while failing to achieve any meaningful change can be penalized by being denied the privilege of governing us. The debate is ours to control if we care enough to do so.

\section{The Editorial-Writing Team}

Matthew B. Stanbrook MD PhD, Amir Attaran LLB DPhil, Ken Flegel MDCM MSc, Noni MacDonald MD MSc, Barbara Sibbald BJ, Sharon Straus MD MSc and Paul C. Hébert MD MHSc 